\title{
The Haier Group: Improvement Upon Success
}

\author{
Tyler Ben-Jacob \\ Mercy College MBA Program. Strategic Consulting Institute \\ New York, NY \\ doi: 10.19044/esj.2016.v12n1p11 URL:http://dx.doi.org/10.19044/esj.2016.v12n1p11
}

\begin{abstract}
This paper discusses the necessary elements for a company to be successful. It considers internal and external components, including aspects of management, marketing, and employee loyalty. An analysis of the strategies used by the Haier Group, a producer solely of refrigerators in 1984, to rise to a company that dominated the market of white goods by 2014 is presented. After delving into the processes and techniques used by this company to grow into a global enterprise, the discussion elaborates with suggestions that could make this remarkably successful company advance even more in today's market.
\end{abstract}

Keywords: Business, analytics, innovation, growth

\section{Introduction}

There are key elements that need to be incorporated into every successful company. Both internal and external components are critical for consideration. A generic plan for the product or business itself and the related marketing of the product are obviously needed. Growth, and marketing campaigns need careful attention. The distinction between a business plan and a marketing plan is that the former paves the overall direction of the company and the latter creates advertising based on sales projections and product distribution strategies. With sound planning, a company can blossom (Root, 2015).

Top notch management is important for every company that wants to move forward. In addition to providing the guidance a company requires, management needs to develop a good relationship with the employees (Root, 2015).

A good company needs employees who are loyal. Employee relationships as well as employee-management relationships need to be developed. Competitive salaries, health benefits, safe working environments, and opportunities for advancement increase the retention rate of employees. If a company has to replace experienced employees too often, 
too many resources will have to be allocated to training and adjusting. This will detract from the focus of staying up-to-date with the industry (Root, 2015).

Money or financing a company is obviously necessary for success. Two generic avenues of financing for a company are external from investors or lenders, and internal from company generated revenues. Without sufficient financial support, no company can survive for long (Root, 2015).

Integrity within the company is a key component as well, especially when finances are concerned. A most obvious illustration of this is the Enron case. Enron was an American oil company based in Houston, Texas. At one point it was rated as the world's most innovative large company. Briefly, the company violated accounting rules and was forced into bankruptcy (Healy \& Palepu, 2013).

For a long time, the reputation of the company was stellar and many kept on buying the stock while at the same time, the company made many high-risk deals, some of which were outside the company's typical asset risk control process. Many of these deals failed. Enron's stock price and debt rating crashed because of loss of investor and creditor trust. The company was deceptive with regard to its complicated financial dealings, many of which were erroneous and hidden. The company's lack of transparency in reporting its financial affairs, followed by financial statements disclosing billions of dollars of omitted liabilities and losses, contributed to its fall. The Chief Financial Officer Andrew Fastow and other executives not only misled Enron's board of directors and audit committee on high-risk accounting practices, but also pressured Andersen, Enron's external auditor to ignore the issues. In 2001 Enron declared bankruptcy. Thousands of employees lost their work and their retirement savings. The investors in Enron, most of the company's employees, lost billions of dollars as Enron's shares shrank to penny-stock levels. Ultimately, the company admitted that it had misstated its income and that its equity value was a couple of billion dollars less than its balance sheet indicated (Healy \& Palepu, 2013). This a case of "cooking the books." Clearly this was an issue of a lack of integrity.

Sandra Williams (2011) feels that above and beyond business codes, even if they are written, honesty, fairness, concern of others and achievement are fundamental work values. Kaplan and Norton (2005) think there are four perspectives that need to be addressed for a business to succeed. They are the financial perspective, the customer perspective, the internal business perspective, and the innovation and learning perspective. Their stance is that no one set of measures should take precedence to the exclusion of any other. 
Nohria, Joyce, and Roberson (2003) feel "What Really Works" is excelling at the following four management practices: strategy, execution, culture, and structure. The following four secondary practices, talent, leadership, innovation, and mergers and partnerships are important; rather than a company spreading itself too thin, a company should incorporate two of the latter four on which to focus. In fact when using all four of the secondary principles as opposed to just two of them, there was no significant difference in a company's success. Their idea is that a " $4+2$ " formula works and they encourage companies to focus on the secondary areas of their choices.

There are different perspectives on what it takes to have a successful company; yet the underlying foundation that attention and care must be given to both the internal and external workings are a necessity. No matter how successful a company is, constant review of its operation will show there is always room for improvement. In this paper, I will examine the Haier Company which is a classic case of success. I will then be so bold as to make suggestions as to how even this company might improve upon itself.

\section{Background}

The Haier Group founded in 1984 was strictly a refrigerator producer. In 2014 according to data research Haier had the largest market share of white goods. This was the $6^{\text {th }}$ year in a row they dominated the appliance market. What has happened in this timeframe that made a company grow into a global brand from something almost unknown? We will start with the first step the company took into obtaining the reputation they have today. That first step was the hiring Zhang Ruimin. Little did they know but this eventual CEO was going to turn the company around. The company when he showed up was in poor condition. Unskilled workers, low productivity, and most importantly to the company, they were producing an inferior product. It was not a money making business, rather it was operating at a loss. With a lot of work ahead, Zhang was determined to turn it around. He accomplished this by creating a whole new corporate culture with new rules. In addition he revamped the strategies of the business and set up a management control system based on incentives. He was ready to create a whole new Haier Group (Lau \& Han 2007). He wanted Haier to go higher.

Haier's change can be thought of in four stages: brand building, diversifying, globalization and global branding. Zhang started with his undisciplined workers. He created a set of everyday rules that once inculcated into the daily lives of his workers would then make them more disciplined. Next he created restrictions on the sales and quality of the 
company's products. If these quality restrictions were not met, the products were destroyed. Eventually the company became well known for good refrigeration products. Then Zhang moved the company beyond just making refrigerators. The next step was to expand the product line, and they went on to washing machines, televisions, and air conditioners. This all went very well, but their reputation was only growing in China. Outside the country the company's products were still not recognized. Zhang then began to push products outside of the country; but other countries had trouble understanding how to use Haier's products and their benefits. Haier offered a comparison to show how their company's products outperformed that of the competition. The comparison was successful. Eventually Haier's product list had as many as 96 items and was available in 30 different countries (Lau \& Han, 2007).

Zhang understood that there is more to a successful company than just a good product. He created a corporate culture and management control system for which people wanted to work and liked to work. The main principle of their corporate culture was innovation. To create camaraderie and teams among workers Haier implemented an employee handbook explaining the beliefs of the company. It went from "process approach to people approach” (Lau \& Han, 2007). He created the "Strategic Business Unit System.” It was a “Mini Mini” company system essentially making all employees their own bosses. By putting faith into each one of his workers he created a better environment and a more productive one. The company ran well. If one employee significantly showed his dedication, hard work, creativity and exceptional performance he was rewarded. To further escalate the competitive edge in the company, Zhang encouraged each person to outperform his coworker; this created even more success for the company as a whole. Haier had an event in which members would get up on a pedestal and announce any infractions or complaints they had with how operations were occurring or with the actions of a company member. They would announce in front of their coworkers what problems or issues they had. Essentially this was airing out dirty laundry publicly. There was also as "10-10" policy whereby the lowest performing $10 \%$ of employees were fired and the highest $10 \%$ were given the option of further training. (Lau \& Han, 2007).

Other sectors of the company needed work too. They needed to remove any dichotomy between upper level management and lower level workers. They placed more emphasis on HR to keep the staff as a whole happy and set forth rules, ethics, and value systems (Lau \& Han, 2007).

Finances needed restructuring as well. They received more work than a normal finance division in a company would generally. There was an increased expectation for the financial division to be involved in planning 
and consulting, as well as take part in accounting activities such as allocation of revenue and cost to individual employees. By distributing more work of a diversified nature, Zhang was creating a company where everyone played an essential role in each other's daily lives. To work successfully, employees needed to do it together (Lau \& Han, 2007).

These are some of the highlights from a company who exceeded everyone's expectations by revamping a corporation all around and becoming a company whose global quality products are everyday household names.

By harnessing their goals and working towards a global culture, Haier was preparing itself for a better and more lucrative future. Every day they were becoming a stronger and more competitive maker of goods with which the other brands were going to have to compete.

It is somewhat presumptuous to suggest improvement for the Haier Group given its level of success; nevertheless I will give my opinion.

\section{Discussion}

A company needs to constantly review its operation from all perspectives, internally and externally, from the viewpoints of management, finances, and employee relations. Zang understood this.

At Haier, there was a mechanism for feedback from the employees. This is a positive in general, but one could take umbrage with this methodology. If an employee felt something was wrong, he stated it publicly. This could lead to negative repercussions. An improvement on this would be the formation of focus groups to discuss the issues that surround the employees. Then, if an anonymous report were sent to a higher level of management anonymously, the results would be better.

At Haier, there is a "fix-it" strategy that is in play as opposed to a "best practices strategy." A fix-it strategy addresses only things that do not work well and ideas on how to improve the deficiency or deficiencies, whereas a best practice strategy focuses on methods or technologies that have consistently been successful and uses them as benchmarks. The former works, but why not incorporate a best practices strategy as well. Haier's “ $10-10$ scheme”, where $10 \%$ of the employees, those at the bottom $10 \%$ of achievement get fired and the top $10 \%$ get a chance for improvement might be deemed unjust. It is possible that someone is performing poorly because of a personal situation. A less drastic tactic would be to give such an employee a warning and a year or so to improve. Employees who are not in the top $10 \%$ might be given the opportunity to further their education, etc. if they so choose. Obviously, this "10-10 rule" promotes competition but it seems too rigid. 
The aforementioned suggestions are internal and of the human resource type. The Haier Group could take note of the following production improvements as well.

Right now the Haier Group is dependent on a compressor for their appliances that is manufactured in Japan (He \& Wong, 2013). Obviously, they are subject to the price and terms set by the manufacturer of this component. Haier would do better to develop alliances with other manufacturers to expand its possibilities. Haier should consider manufacturing its own compressor, if it is feasible. This way they would not be beholden to the prices and terms of any other manufacture.

With its amazing growth, the Haier Group expanded into different units such as pharmaceuticals, for example (He \& Wong, 2013). Whereas expansion often brings in greater revenue, Haier should consider removing some of the divisions which are not its mainstay. White products is a natural extension from refrigerators, but elimination of divisions such as pharmaceuticals which is a bit of a stretch, would produce an increase in cash inflow that could be used to enhance other, stronger divisions.

Right now, Haier does not have its own local logistic centers in China. Making local centers responsible for their accounting systems would benefit the company (He \& Wong, 2013).

In addition, with regard to the internal reporting system, Haier's Strategic Business Unit supports a daily reporting system as opposed to a traditional one that is at most monthly (Lau \& Han, 2007). While this certainly keeps closer track about what is happening, it seems to me like overkill. Too many reports are being generated and wasting manpower and other resources. Even if the company wanted to keep close watch on its operations, these daily reports could become weekly or bi-weekly and have a similar effect.

There is quite a bit of competition in China now. People are looking for the best buy in products. Haier needs to produce simple, functional goods to stay competitive (He \& Wong, 2013). Haier's philosophy has always been to produce a superior product. Haier cannot afford to always produce the highest quality item if the cost is too high and it will be passed on to the consumer.

Haier has an international reputation, but one that needs strengthening in the United States. Some statistics from 2012 that reflect the international success of Haier are:

- $\quad$ "Euromonitor International, the global leader in consumer market strategy research, ranked Haier as the number one major appliance brand in the world with an $8.6 \%$ retail volume share.

- $\quad$ Haier is the number one manufacturer of refrigeration appliances in the world with $14.8 \%$ retail volume share. 
- Haier is number one brand of Refrigeration Appliances in the world with $13.7 \%$ retail volume share.

- Haier is the number one Freezer manufacturer in the world with $18.6 \%$ retail volume share.

- Haier is the number one brand of Home Laundry in the world with 11.8\% retail volume share (PRNewswire, 2012).”

Studies show that Haier needs improved marketing strategies in the United States. A survey was conducted with regard to opinion of Haier as a supplier of home appliances. The results of respondents were 54 percent reported a neutral attitude towards Haier as a home appliance supplier. Another 39 percent evaluated the brand in a positive light in 2015. (Statista, 2015). Less than $20 \%$ of Americans are familiar or somewhat familiar with the Haier brand of products. Haier has had to downplay the country of origin of its products as they reach out to Americans. The feeling is that Americans are not trusting of products made in China (VOA, 2014)

\section{Conclusion}

The Haier Group is a remarkable example of a successful company. Its turnaround was truly amazing. Yet, as we have demonstrated, there is always room for improvement, especially as market conditions change. The only way to realize whether or not a strategy will improve a company, is to implement it and evaluate the results.

\section{References:}

He, Muzi, Wong, K.C. (2013). An Analytical Study of Strategic Management of Haier. Journal of Contemporary Management. Retrieved from http://www.bapress.ca/jcm/jcm2014-2/1929-0128-2014-02-01-14.pdf Healy, Paul, Palepu, Krishna. (2013). The Fall of Enron, Harvard Business School. Retrieved from https://cb.hbsp.harvards.edu/cbmp/access/36782373 Kaplan, Robert, Norton, David. (1992). The Balanced Scorecard. Harvard Business Review. Retrieved from https://cb.hbsp.harvards.edu/cbmp/access/36782373

Lau, Amy, Han, Jun. (2007). Haier: Management control on a Tactical Level. The Asia Case Research Center. Retrieved from https://cb.hbsp.harvards.edu/cbmp/access/36782373

Nohria, N., Joyce, W. Roberson, B. (2003). What Really Works, Harvard Business Review, Retrieved from https://cb.hbsp.harvards.edu/cbmp/access/36782373

PR Newswire. (2012). Haier Ranked the \#1Global Major Appliances Brand for the $4^{\text {th }}$ Consecutive Year-Euromonitor. Retrieved from prnewswire.com Root, George. N. (2015). What Key Elements Make a Company Successful, Hearst Newspapers, LLC. Retrieved from 
http://smallbusiness.chron.com/key-elements-make-company-successful22315. Html

Statista: the Statistics Portal (2015) Retrieved from http://www.statista.com/statistics/452290/united-states-haier-opinion/ Williams, Sandra. (2011).Engaging Values in International Business Practice, Indiana University. Retrieved from https://cb.hbsp.harvards.edu/cbmp/access/36782373 VOA (Voice of America) (2014). Chinese Brands Little Recognized in US, but Innovation Helping. Retrieved from http://www.voanews.com/content/chinese-brands-little-recognized-in-usbut-innovation-helping/2578088.html 